\title{
Gegenvorschlag der FMH zur Einheitskasseninitiative
}

Bundesverfassung Art. 117:

Kranken- und Unfallversicherung

1 Der Bund erlässt Vorschriften über die Kranken- und die Unfallversicherung.

2 Er kann die Kranken- und die Unfallversicherung allgemein oder für einzelne Bevölkerungsgruppen obligatorisch erklären.

\section{BV Art. 117 (Abs. 3-5 neu)}

3 Der Bund beauftragt die Krankenkassen, die soziale Krankenversicherung in Zusammenarbeit mit den Kantonen, den Leistungserbringern und den Patientinnen und Patienten durchzuführen.

4 Die Krankenkassen haben eine demokratische Struktur und nehmen die sozialen und finanziellen Interessen ihrer Versicherten wahr.

5 Die Krankenkassen betreiben ausschliesslich die soziale Kranken- und Unfallversicherung und haben keine strukturellen, organisatorischen oder wirtschaftlichen Verbindungen mit andern Tätigkeiten.

\section{Erläuterungen}

\section{Zu Absatz 3}

Die konstruktive Zusammenarbeit zwischen den Krankenversicherern gemäss KVG, den Kantonen und den Leistungserbringern sowie den Patientinnen und Patienten ist von zentraler
Bedeutung. Die Probleme im Gesundheitswesen können nur gemeinsam gelöst werden.

\section{Zu Absatz 4}

Dank demokratischer Struktur bestimmen die angeschlossenen Versicherten die Geschicke der Kasse und haben volle Transparenz. Für die Umsetzung in Art. 12 Abs. 1 KVG bieten sich als Organisationsform insbesondere der Verein, die Stiftung, allenfalls die Genossenschaft an.

\section{Zu Absatz 5}

Die anerkannten Krankenkassen beschränken ihre Tätigkeit auf die soziale Krankenversicherung (Krankenpflegegrund- und Taggeldversicherung) sowie die soziale Unfallversicherung. Zusatzversicherungen und Rechtsschutzversicherungen beispielsweise sollen weder von der Krankenkasse selbst noch in Kooperation mit Dritten angeboten werden. Der Verzicht auf KVG-fremde Tätigkeiten und auf strukturelle, organisatorische oder wirtschaftliche Verbindungen mit Dritten stellt die Unabhängigkeit und Transparenz der Kasse sicher und vermeidet Interessenkonflikte.

Die Umsetzung auf gesetzgeberischer Ebene erfolgt in Art. 12 Abs. 2 KVG: Beschränkung auf die ausschliessliche Tätigkeit im Rahmen des KVG und Verzicht auf Kooperationen mit Dritten. 